\title{
Data Visualization as Communication: The Role of Business Communication in Data Analytics
}

\author{
Stephanie Kelly ${ }^{1}$, Tiffany L. S. Tovey ${ }^{2}$ \\ ${ }^{1}$ North Carolina A\&T State University, Greensboro, NC, USA \\ ${ }^{2}$ University of North Carolina, Greensboro, Greensboro, NC, USA
}

\section{Introduction}

The standards for Accreditation to Advance Collegiate Schools of Business requires that business schools offer curriculums that are "current, relevant, forward-looking" (Association to Advance Collegiate Schools of Business [AACSB] International, 2020 , p. 37). Today, there is arguably no more current, relevant, or forward-looking curriculum content for business schools than those topics pertaining to data analytics. Data analytics have become "an integral part of planning and decision making in business" (Clayton \& Clopton, 2018, p. 1). Indeed, students from a variety of business majors require basic statistical knowledge as well as the ability to interpret and communicate results to be prepared for the workplace in any business degree (Pan et al., 2018).

Numerous researchers have investigated the most efficient ways to infuse data analytics throughout business curriculum. Publications of such pedagogical research have focused on topics such as big data (Enget, Saucedo, \& Wright, 2017), data security (Ashraf, 2017), and data mining (Wu, Mai, \& Yu, 2015). Aasheim, Williams, Rutner, and Gardiner (2015) found that the majority of data analytics courses offered by business schools

Received: Oct 13, 2021 Revised: Jan 4, 2022 Accepted: Jan 17, 2022 Corresponding author: Stephanie Kelly

North Carolina A\&T State University, 1601 E. Market Street, Greensboro, NC, USA

Tel: +1-336-285-4903, E-mail: sekelly@ncat.edu

This is an Open Access article distributed under the terms of the Creative Commons Attribution Non-Commercial License (http://creativecommons.org/licenses/ by-nc/4.0/) which permits unrestricted non-commercial use, distribution, and reproduction in any medium, provided the original work is properly cited.

Copyright ( $\odot 2022$ Korean Association for Business Communication. place an emphasis on how to use analytics programs and prepare data. Yet, the ability to effectively communicate results is an integral part of data analytics training for any business major (Pan et al., 2018; Wymbs, 2016).

\section{The Intersection of Data Visualization and Business Communication}

Infographics are visual communication tools in the form of graphics that convey, not just accompany, information (Smiciklas, 2012). A data visualization is a special type of infographic that strives to quantify and classify data (Few, 2004). Like all infographics, data visualizations rely on the relationships between visuals and metaphor to work as a standalone piece of information (Smiciklas, 2012). This means that a well-designed data visualization does not need to be supplemented by additional text or dialog and instead is designed to convey all that the audience needs to know about the data it is displaying (Kelly, 2015).

Kelly, Croucher, Sandel, and Yu (2018) found that though communication of data for business can take place in written, oral, and visual form, data visualizations are the most effective in cross-cultural business engagements. Written and oral communication training are common in business communication courses, but visual communication training is uncommon (Kelly, 2015). In the last decade, Toth (2013) made a call for incorporating more infographics design training into business communication, especially the building of data visualizations.

When it comes to data analytics training, effective data visualization has become synonymous with communication competence. A publication by the Business-Higher Education 
Forum (2018) overviews that there are eight typologies of data analytics skills a business student must have to be considered a well-rounded data generalist for the workplace. Their list of data analytics competencies for business list "Data Visualization and Communication" as their fourth competency (Business-Higher Education Forum, 2018, p. 1). Similarly, Udacity (2014) in an overview of data analytics competencies lists "Communication and Data Visualization" as one of their seven competencies (p. 13). Further, Verma, Yurov, Lane, and Yurova (2019) more recently found data visualization and communication to be linked critical jobs skills in job postings for business analysts and business intelligence analysts. Indeed, whether data visualization is currently listed in business communication curriculum as a core learning goal, it seems that industry has recognized data visualization as a core business communication skill for data analytics.

\section{The Difficulty of Teaching Data Visualization}

Effectively preparing business majors to engage with data analytics in the workforce is a problem in higher education because faculty often lack the proper holistic training needed to connect skillsets (Clayton \& Clopton, 2018). In the case of data visualization and business communication, this may be a concern. Many business communication faculty have backgrounds in linguistics and rhetoric, which are not fields heavy in quantitative data. As such, it may be that data visualization is seldom discussed in this discipline because faculty do not feel they have the statistical background needed skillset to incorporate it. If business students are not taught effective data communication in business communication, where then will they learn it?

Perhaps to begin serious consideration of how to incorporate data visualization into the business communication curriculum, the field of business communication needs to take a step back and look at the larger role of data visualization in society rather than focusing on the strong connection between data visualization and statistics. The remainder of this essay proposes options for how business communication faculty may begin to integrate data visualizations into their curriculum, even if they are uncomfortable with the technical or quantitative components of advanced data visualization, such as needed for data analytics.

\section{Keep it Simple}

Students can have an introduction to data visualization in business communication, thinking through the purpose of the message and the audience they are communicating to without using complicated datasets or needing to conduct a high level of statistics. Data visualizations are a way of explaining evidence to an audience, so business communication faculty are well equipped to help student think through audience analysis components of data visualization. Simple assignments like an infographic résumé can help students think through these communication principles (Kelly, 2015). Exposure to basic infographic designs encourages students to think critically about information (Dunlap \& Lowenthal, 2016), which will prepare them for when they are ready to incorporate higher level statistical or technical skills. Professors who are more worried about teaching the technology component than the analytical component need not fear their software limitations because students consistently demonstrate that they enjoy playing with technologies to create simple data visualizations (Butler, 2011), and data visualization for beginners are easily created in PowerPoint with the aid of templates and smart art (Kelly, 2015). So, simple data visualization activities in business communication courses can become a foundational learning experience for students and instructors.

\section{Talking about Design rather than Designing}

Creating an effective data visualization requires strategic thinking to guarantee clarity and accuracy (Shanks, Izumi, Sun, Martin, \& Byker Shanks, 2017). Not all designers do this successfully, thus students can learn a lot from discussing data visualizations that have already been published (Zhang, 2019). Looking at published data visualizations gives students an opportunity to reflect on who the visualization was prepared for and how the design of the visualization influences the message conveyed to the audience. Further, talking about data visualizations that have been published gives students the opportunity to think critically about the ethics of data visualization when misleading examples are shown (e.g., those that show percentages not adding to $100 \%$, those that start axes somewhere other than the origin to skew proportions). It can even be worthwhile to discuss whether an infographic was adequately designed to stand on its own, or whether it is dependent upon a larger story, a lesson similar to what Toth (2013) recommended for business communication curriculum.

\section{Team Teaching or Cross Collaborations}

Another option for teaching data visualization is to collaborate with quantitative courses. Team teaching and/or cross-listing of courses that readily incorporate data analytics such as economics, statistics, or accounting can allow students to simultaneously learn the quantitative and technical skills required to create data visualizations while simultaneously working to learn the communication components of such tasks in business communication. For example, a quantitative professor may focus on the technical steps behind coding a visualization of a par- 
ticular dataset, while a collaborating business communication professor focuses on discussing what the visualization conveys, whether the message is complete, and whether the message could be misleading. Team teaching exercises that would allow a single data visualization assignment to be developed across courses would allow students to receive ample instruction for all components of data visualization.

\section{More than One Class}

A final option is to spread business communication content across two courses. Recent research on the business curriculum has concluded that one communication course is simply not enough (Clokie \& Fourie, 2016). Having a lower-level course that focuses purely on soft-skills removed from quantitative reasoning and an upper division course that focuses on communication with data would allow business communication faculty who are and are not comfortable teaching data visualization to work with students in the course in which they can best serve the students.

\section{Conclusion}

Data visualization is a critical skillset for today's business majors (Pan et al., 2018). Given the established critical need of data communication/visualization for the workforce (c.f., Pan et al., 2018; Wymbs, 2016), it is clear that these skills must be incorporated into the business curriculum. Unfortunately, it is unlikely that those who teach data visualization from a technical or quantitative background are fully trained to teach these compositions as messages rather than outputs of code and analyses (c.f., Clayton \& Clopton, 2018). To fill this gap, business communication educators must further explore how they can incorporate data visualization into their classroom. The notion of incorporating data visualization into business communication need not feel intimidating, as though business communication educators must suddenly be experts in programming and statistics. Instead, business communication faculty are well equipped to introduce students to the communicative aspect of data visualization and prepare them to evaluate the effectiveness of those messages.

\section{References}

Aasheim, C. L., Williams, S., Rutner, P., \& Gardiner, A. (2015). Data analytics vs. data science: A study of similarities and differences in undergraduate programs based on course descriptions. Journal of Information Systems Education, 26(2), 103-115.

Ashraf, R. (2017). Scraping EDGAR with python. Journal of Educa- tion for Business, 92(4), 179-185.

Association to Advance Collegiate Schools of Business International. (2020). 2020 guiding principles and standards for business accreditation. Tampa, FL: AACSB International.

Business-Higher Education Forum. (2018). Generalist digital credential: KSAs and learning outcomes. Retrieved from https:/gamescdn.washingtonpost.com/notes/prod/default/documents/76b9407cd982-4ffb-a8a3-43d53aa1747f/note/b617e77d-1928-4c6f-9cfa4831124e6886.pdf

Butler, S. H. (2011). Teaching rhetoric through data visualization. Communication Teacher, 25(3), 131-135.

Clayton, P. R., \& Clopton, J. (2018). Business curriculum redesign: Integrating data analytics. Journal of Education for Business, 94(1), 57-63.

Clokie, T. L., \& Fourie, E. (2016). Graduate employability and communication competence: Are undergraduates taught relevant skills? Business and Professional Communication Quarterly, 79(4), 442-463.

Dunlap, J. C., \& Lowenthal, P. R. (2016). Getting graphic about infographics: Design lessons learned from popular infographics. Journal of Visual Literacy, 35(1), 42-59.

Enget, K., Saucedo, G. D., \& Wright, N. S. (2017). Mystery, Inc.: A big data case. Journal of Accounting Education, 38, 9-22.

Few, S. (2004). Eenie, meenie, minie, moe: Selecting the right graph for your message. Intelligent Enterprise, 7, 14-35.

Kelly, S. (2015). Teaching infographics: Visually communicating data for the business world. Business Education Forum, 59(3), 35-37.

Kelly, S., Croucher, S., Sandel, T. L., \& Yu, F. (2018). Infusing infographics into the business curriculum: A study of infographic interpretations in China, New Zealand, and the United States. Global Advances in Business Communication, 7(1), 3.

Pan, K., Blankley, A. I., Mazzei, M. J., Lohrke, C. F., Marshall, J. B., \& Carson, C. M. (2018). Surveying industry advisors to select data analytics topics for all business majors. The International Journal of Management Education, 16(3), 483-492.

Shanks, J. D., Izumi, B., Sun, C., Martin, A., \& Byker Shanks, C. (2017). Teaching undergraduate students to visualize and communicate public health data with infographics. Frontiers in Public Health, 5, 315.

Smiciklas, M. (2012). The power of infographics: Using pictures to communicate and connect with your audiences. Indianapolis, IN: Que.

Toth, C. (2013). Revisiting a genre: Teaching infographics in business and professional communication courses. Business Communication Quarterly, 76(4), 446-457.

Udacity. (2014). Ultimate skills checklist for your first data analyst job. Retrieved from http://1onjea25cyhx3uvxgs4vu325. wpengine.netdna-cdn.com/wp-content/uploads/2014/12/ 
UdacityUltimateSkillChecklistForYourFirstDataAnalystJob.pdf

Verma, A., Yurov, K. M., Lane, P. L., \& Yurova, Y. V. (2019). An investigation of skill requirements for business and data analytics positions: A content analysis of job advertisements. Journal of Education for Business, 94(4), 243-250.

Wu, C., Mai, F., \& Yu, Y. (2015). Teaching data mining to business undergraduate students using R. Business Education Innovation
Journal, 7(2), 64-73.

Wymbs, C. (2016). Managing the innovation process: Infusing data analytics into the undergraduate business curriculum (lessons learned and next steps). Journal of Information Systems Education, 27(1), 61-74.

Zhang, J. (2019). Incorporating data analytics in accounting. Business Education Forum, 73(3), 14-16. 